\title{
Uma Trajetória do Ensino de Matemática em SÉRIES INICIAIS do ENSINO FUNDAMENTAL: VESTÍGIOS HISTÓRICOS PRESENTES EM UMA ESCOLA LOCALIZADA NA ZONA RURAL DA AMAZÔNIA BRASILEIRA
}

\author{
A TRAJECTORY OF MATHEMATICS EDUCATION IN ELEMENTARY SCHOOL: \\ HISTORICAL TRACES PRESENT IN A SCHOOL LOCATED IN THE \\ COUNTRYSIDE IN THE BRAZILIAN AMAZON
}

DOI: http://dx.doi.org/10.23926/RPD.2526-2149.2019.v4.n1.p61-79.id367

\section{Cristiane Vilmer \\ Corrêa \\ Licenciada pela \\ Universidade Federal de \\ Rondônia (UNIR) \\ crt.vilm@gmail.com}

\section{Marlos Gomes de Albuquerque \\ Doutor em Educação, \\ Ciências e Matemática \\ (UFMT) \\ Professor do Departamento de Matemática e Estatística (UNIR) \\ marlos@unir.br}

\begin{abstract}
Resumo: O presente trabalho teve por objetivo investigar os vestígios do ensino de Matemática numa escola rural situada em Presidente MédiciRondônia. O estudo foi desenvolvido a partir das Histórias da Educação Brasileira e do estado de Rondônia, interligando-as à história da educação local. Metodologicamente fundamentou-se em fontes documentais por meio de triangulação com a narrativa de uma professora e da vivência da autora deste trabalho enquanto ex-aluna da escola, tendo como base os escritos de alguns teóricos da História, da História da Educação Matemática e da História da Educação de Rondônia. Teve como pergunta de pesquisa: De que maneira se deu a trajetória do ensino de Matemática em uma escola do interior rondoniense? Dentre os resultados destaca-se que o contexto histórico em que se originou a educação rondoniense é marcante em todo seu processo de organização e implementação, somente sendo viabilizada segundo as exigências das necessidades da sociedade que se formava no estado. O depoimento da professora elucida detalhes sobre a escola e o ensino de matemática que é evidenciado no caderno de atividades com práticas contextuais. As permanências e rupturas do ensino são designadas, principalmente, pelas condições sociais que cercam a comunidade escolar onde encontrou-se características da educação tradicional.
\end{abstract}

Palavras-chave: História da Educação Matemática; Zona Rural; História da Educação Rondoniense.

\begin{abstract}
The present work had the objective of investigating the traces of mathematics teaching at the rural school located in Presidente-Médici Rondônia. The study was developed from the Histories of Brazilian Education and the state of Rondônia, linking them to the history of local education. Methodologically, it was based on documentary sources by means of triangulation with the narrative of a teacher and the experience of the author of this work a former student of the school, based on the writings of some historical theorists, the History of Mathematical Education and the History of Education of Rondônia. He had as a research question: In what way was the trajectory of teaching mathematics in a school in the interior of Rondon? Among the results, it is worth highlighting that the historical context in which Rondonian education originated is remarkable throughout its organization and implementation process, only being made feasible according to the needs of the society that was formed in the state. The teacher's testimony elucidates details about the school and its I mathematical teaching is evidenced in the activity book with contextual practices. The permanences and ruptures of education are designated, mainly, by the social conditions that surround the school community. where characteristics of traditional education.
\end{abstract}

Keywords: History of Mathematics Education; Countryside; History of Rondonian Education. 


\section{INTRODUÇÃO}

O contato com a historicidade do ensino de Matemática na Escola de $1^{\circ}$ Grau Floriano Peixoto, localizada na zona rural do interior amazônico, no município de Presidente Médici em Rondônia, tem início em 1997, quando aos seis anos de idade comecei a vivenciar este ambiente escolar, me constituindo testemunha ocular. Com o passar dos anos, próximo a concluir a licenciatura em Matemática, em meio às discussões sobre o processo de ensino desta área de conhecimento, veio a motivação de retornar àquele espaço escolar e realizar uma pesquisa tendo por objetivo compreender como se deu o processo de ensino de matemática. Portanto, uma investigação no campo da História da Educação Matemática (HEM).

De que maneira a HEM permeou este trabalho?

Por construir articulação entre história e o ensino de Matemática, por buscar compreender como historicamente se constituiu o processo de ensino e aprendizagem de Matemática e, entremeio a esse processo, identificar de que maneira teve influência nas práticas pedagógicas presentes na escola. Ademais assim como a História, a História da Educação Matemática se constitui como uma área de conhecimento imbuída em responder às questões referentes ao passado a partir do olhar do pesquisador no tempo presente. Nesta pesquisa buscamos investigar a seguinte questão: De que maneira se deu a trajetória do ensino de Matemática em uma escola do interior rondoniense?

O que foi feito para investigar esse processo?

Contextualizamos este trabalho perpassando fragmentos das histórias da educação brasileira e rondoniense, a fim de caracterizar o espaço social, econômico e político que influenciaram a construção da Escola Municipal Floriano Peixoto, nosso lócus de estudo. Este trabalho foi construído mediante uma pesquisa de documentos acerca da escola (atas letivas, fotos, cadernos de atividades) e de análise de acontecimentos relatados por uma professora.

Mas o que motivou a construção deste trabalho no campo histórico?

A nossa condição de testemunha ocular com esta escola trazem lembranças no exercício da memória, momentos e detalhes felizes que por vezes deixam saudades. O passado pertence a todos e a escrita da história não é propriedade de um único historiador, ou seja, "qualquer um pode apropriar-se do passado da educação [...] e contar a sua história da maneira que assim o desejar" (VALENTE, 2013, p. 23).

Este trabalho não é uma cópia do passado, nem um resgate da história, mas sim uma incursão por meio de seus vestígios que possibilitaram a presente construção histórica, 
elaborado sob a "abordagem segundo a qual praticar historiografia não é 'resgatar o passado', mas problematizar o passado à luz do presente" (GARNICA, 2015, p 44).

\section{OS PRIMEIROS INDÍCIOS DE ESPAÇO ESCOLAR SOB A TUTELA DA IGREJA: UM POUCO DE HISTÓRIA EDUCACIONAL DO BRASIL}

Concebemos que "A distinção entre passado e presente é um elemento essencial da concepção do tempo. É, pois, uma operação fundamental da consciência e da ciência históricas" (LE GOFF, 2003, p. 207), assim, nesta relação indissociável entre passado e presente, não é possível ignorar o passado, pois cairíamos na incompreensão do tempo presente. Imbuídos na perspectiva de situar a escola rural objeto da presente pesquisa, buscamos compreender como emergiram os primeiros movimentos escolares no Brasil e interpretar os resquícios deixados no decorrer do tempo.

Os vestígios nos levaram a chegada dos Padres Jesuítas ao Brasil Colônia no ano de 1549. Estes religiosos ficaram assim conhecidos por pertencerem à chamada Companhia de Jesus, congregação criada em Paris no ano de 1534, tendo como fundador o Padre Inácio de Loyola. Em sua trajetória ao longo dos tempos, esta Congregação passou a ser reconhecida principalmente por seu trabalho missionário e educacional.

Mas por que vieram para o Brasil?

A Igreja Católica realizou durante os anos de 1545 a 1563 o seu $19^{\circ}$ Concílio, que ficou conhecido como o Concílio de Trento. Em sua IV Sessão, ocorrida em 8 de abril de 1546, este Clero redefiniu a Igreja Católica como comunidade de fé, magistério e autoridade e prescreveu que a comunidade dos seus fiéis "incluía necessariamente todas as populações gentias das novas terras conquistadas por espanhóis e portugueses, onde as novas ordens fundadas para combater a heresia, como a Companhia de Jesus, deviam exercer o magistério e o ministério da Igreja" (HANSEN, 2000, p. 20).

O ensino era voltado principalmente para a leitura e escrita. Com relação à "matemática, sabe-se muito pouco, mas onde ocorria o ensino desta disciplina, se tratava de abordar as operações aritméticas, razão, proporção e geometria euclidiana" (OLIVEIRA, 2009, p. 8).

\subsection{A MULHER No BRASIL COLÔNIA: ESPOSA DEDICADA, MÃE AMÁVEL E PROFESSORA DE OFÍCIO}

A Escola de $1^{\circ}$ Grau Floriano Peixoto durante seu curto tempo de existência, nunca teve um professor do sexo masculino. As escolas primárias brasileiras, sejam elas rurais ou urbanas, por muito tempo tiveram seu corpo docente composto em quase totalidade por mulheres. 
A mulher sempre teve participação em massa na Educação?

No período de 1500 a 1822, sendo o Brasil colônia de Portugal, a mulher independentemente de sua etnia ou condição social, tinha sua educação voltada para a manutenção da casa, cuidados com o marido e filhos, devendo ser submissa ao marido, regrada aos afazeres domésticos, calada aos ouvidos da sociedade da época. A instrução escolarizada era dada estritamente aos filhos homens dos colonos, indígena e de senhores.

A primeira reivindicação para que as mulheres também tivesse acesso à educação partiu da comunidade indígena. Diferentemente da cultura portuguesa, os indígenas não excluíam das mulheres o acesso ao conhecimento. Para os Padres Jesuítas a educação feminina influenciaria a formação moral das famílias brasileiras. Foi apenas no século XVII que por meio dos conventos as mulheres não indígenas começam a ser alfabetizadas e também recebem aulas de órgão, música, cantochão e trabalhos domésticos.

Um importante ponto de inflexão ${ }^{1}$ concernente à conquista para a educação feminina, ocorre em 1862 com a chamada Escola Normal ${ }^{2}$. Era um curso voltado para as mulheres funcionando em dias alternados ao curso dos homens. Quando a mulher foi aceita e a escola passou a ser mista, gerou muito estranhamento e discussões na sociedade, provocando rupturas no modelo de ensino.

Todavia, as mulheres ainda eram tidas como um ser inferior, haja vista que alguns saberes ainda lhes eram negados, como álgebra e geometria, por exemplo. A cultura social da época considerava que a capacidade de aprender era dotada aos homens, como seres supremos. Dessa maneira, a instrução feminina não era necessária, pois as mulheres eram inferiores e lhes faltavam inteligência.

A busca feminina pela sua instrução e profissionalização começa a ser notada no final do século XIX, onde se acentua um processo de feminização do magistério, advindo também da procura do homem por uma função mais rentável.

O papel da mulher na difusão do ensino escolar foi muito importante na história da educação. E, mesmo hoje, depois de tantas mudanças sociais, econômicas e políticas, essa importância ainda é presente em nossas escolas. Se bem observarmos, a maior parte dos docentes são mulheres, conforme mostram os dados do Censo da Educação Superior 2016,

\footnotetext{
${ }^{1}$ Momentos cruciais de mudanças e que se tornaram marcos históricos ou pontos de inflexão.

${ }^{2}$ Os primeiros decretos de criação de escolas normais no Brasil remontam às décadas de 30 e 40 do século XIX como consequência das reformas previstas pelo Ato Adicional de 1834. Marcadas por seu conservadorismo, pregava a moral e a ética como absolutas.
} 
donde de um total de 238.919 concluintes de cursos de licenciaturas em todo o país, 184.431 eram mulheres, o que representa $77,2 \%$, enquanto que os homens concluintes eram apenas 54.488 ou $22,8 \%$ do montante (ISO, 2017).

\section{CONTEXTO HISTÓRICO EDUCACIONAL EM RONDÔNIA: VESTÍGIOS DA HISTÓRIA GLOBAL RESSOANDO LOCALMENTE}

De que maneira o atual estado de Rondônia se articula localmente com a trajetória histórica da Educação ocorrida globalmente?

O espaço geográfico hoje tido como estado de Rondônia começa a ser explorado a partir do início do século XVII, quando povos vindos principalmente da Europa chegaram a estas terras, navegando por rios, em busca das drogas do sertão ${ }^{3}$, mercadorias valiosas no mercado estrangeiro.

A Coroa Portuguesa, já no século XVIII, preocupada em defender as áreas fronteiriças e as riquezas brasileiras (principalmente dos espanhóis), passa a investir na região com Expedições Exploradoras e de Limites (MATIAS, 1998). Assim tem início a ocupação das terras que anos mais tarde deram origem ao estado de Rondônia, ação que emerge em meio às descobertas de grandes jazidas de ouro e as denominadas drogas do sertão como cravo, canela, castanha-do-pará, cacau, urucum, plantas de cunho medicinais. Este período culminou com a criação dos primeiros núcleos urbanos.

A partir da segunda metade do século XIX, com o término das drogas do sertão, a Amazônia passa por um período de ocupação sistêmica. A fronteira do território da Amazônia brasileira permaneceria móvel até o início do século XX, quando os contornos políticos do Brasil seriam redefinido, em função da conquista dos territórios do Amapá, Roraima e do Acre.

Em 1913 nesta região em que anos mais tarde passa a ser o estado de Rondônia, é criada a primeira escola designada Escola Municipal Santo Antônio, no município de Porto Velho (Alto do Madeira), que pertencia ao Amazonas e mais tarde passou a pertencer a Rondônia. A criação desta escola pública coincide com a construção da Estrada de Ferro Madeira-Mamoré, onde surgem pequenos espaços urbanos, com alguns comerciantes, operários e agricultores promovendo o desenvolvimento destes (LIMA, 1993).

Com os avanços nesta região da Amazônia, o Presidente Getúlio Vargas cria em 13 de setembro de 1943, o Território Federal do Guaporé, por meio do Decreto-lei n ${ }^{\circ}$ 5.812, composto

\footnotetext{
${ }^{3}$ Por drogas do sertão eram conhecidas as essências como a canela, cacau, pau-brasil, pau-preto entre outras, retiradas do Brasil e comercializadas na Europa.
} 
territorialmente por terras do Sul do Amazonas e do Norte de Mato Grosso. Em 1956, o então Território Federal do Guaporé, por meio da Lei ${ }^{\circ}$ 2.731, tem sua nomenclatura mudada para Território Federal de Rondônia, que chega à condição de estado em 22 de dezembro de 1981.

O movimento educacional em Rondônia, nos anos seguintes, se intensifica com a criação de outras escolas na eminência de atender a crescente necessidade e demanda por vagas escolares. Não diferente dos demais estados brasileiros, há a chegada de instituições de ensino particulares, a exemplo da Escola Pestalozzi (1921); outras, pela incumbência da Igreja Católica, como o Colégio Dom Bosco (1922), fundado por Padres Salesianos; e, ainda, as escolas laicas e públicas, no caso de vários Grupos Escolares (1923).

Com o número de alunos e de escolas em plena expansão, há a necessidade local de uma escola com a finalidade de formar professores para atender o ensino primário. Assim, em 1931, é criado o Colégio Nossa Senhora Auxiliadora no município de Porto Velho, constituindo-se como o primeiro a implantar o Curso Normal rural de nível ginasial para habilitação de Magistério, representando o surgimento da preocupação com a formação docente e o desenvolvimento da educação (LIMA, 1993). Apesar do avanço no âmbito da educação com a chegada da primeira Escola Normal no Estado, tal situação ocorre próximo a completar um século da criação da primeira Escola Normal no Brasil, em 1835, no Rio de Janeiro.

Paralelamente à criação destas escolas, em Guajará-Mirim, em 1923, já funcionavam algumas Escolas de Ofício ${ }^{4}$, tendo cursos de leitura, matemática e profissionais para meninos, enquanto que para as meninas eram apenas cursos de catecismo e prendas domésticas. Esses vestígios da história educacional da mulher retratam a negação à figura feminina do direito ao acesso às outras áreas de conhecimento na concepção de que seus saberes deviam ser restritos.

No ano de 1943, em decorrência da emancipação da região como Território Federal do Guaporé, e considerando ainda o fortalecimento da produção de Borracha ocorrida durante a II Guerra Mundial, inicia-se uma nova fase na história da educação local. A administração do Território passa a ter um papel mais direto nos aspectos de promoção, regularização e manutenção dos sistemas de ensino e da cultura.

O intenso crescimento demográfico iniciado localmente a partir da década de 1970 passa a ser mais preocupante. Neste ínterim, com a necessidade de novas escolas e de mão de obra

\footnotetext{
${ }^{4}$ As escolas de ofícios proporcionavam uma educação voltada para a aprendizagem profissional, sendo resquícios do fracasso industrial sofrido pelo Brasil no século XVIII. Elas surgem em meio à renovação do processo industrial promovido após a vinda de D. João VI, em 1808, para o Brasil, a fim de fortalecer a mão de obra.
} 
qualificada para atender a demanda, a população não espera ações do governo territorial, mas por conta própria toma iniciativa:

[...] muitas das vezes as comunidades anteciparam à ação governamental, instalando escolas em espaços físicos por elas construídos e elegendo para exercer as funções de administração e de docência um de seus membros com mais aptidão. [...] Isto implicou no crescimento do número de escolas funcionando em locais improvisados não adequados (barracas e tapiris) e no aumento do contingente de docentes leigos (LIMA, 1993, p. 21).

Em 1981, com Rondônia na condição de estado, são criadas ações que viabilizam “a instalação de unidades escolares de $1^{\circ}$ e $2^{\circ}$ Graus, [...] a implantação e implementação do Programa Pró-rural de caráter especial, como experiência pedagógica para o meio rural, objetivando adaptar o ensino às peculiaridades das comunidades rurícolas" (LIMA, 1993, p. 24), sendo destinado a formação do aluno da zona rural, de primeira à quarta série o que possibilitou tempos depois a criação da escola lócus deste estudo. O ensino passa a ser responsabilidade dos municípios, sofrendo mudanças em sua organização, quando são definidos: Conselho Estadual de Educação, responsável pelo sistema educacional; Secretaria de Estado da Educação, dito por estabelecimento e manutenção da política educacional; e Secretarias Municipais de Educação.

\section{Contexto histórico do MunicíPIo de Presidente Médici}

Os primeiros registros sobre a origem do atual município de Presidente Médici, localizado no interior amazônico, mais precisamente em Rondônia, datam de 1915, período em que a Comissão Rondon passa pela região, que já era habitada pelos seringueiros do seringal São Pedro do Muqui.

Já sua ocupação se faz a partir da construção da rodovia BR 364, por volta dos anos de 1970, quando a migração no estado se tornou intensa e numerosa. Pesquisas dão conta que os colonos se instalaram em quatro barracas localizadas a $33 \mathrm{~km}$ da Vila de Rondônia, atual JiParaná, ficando o local assim conhecido como Trinta e Três. "Seus moradores, todos agricultores, socorriam de alguma forma os motoristas e passageiros de viaturas que ficavam retidas em um imenso atoleiro conhecido por Muqui, nas proximidades do rio com mesmo nome" (MOREIRA, 2004, p. 15).

Em 30 de junho de 1973, por meio de um plebiscito, a então Vila 33 ganha um novo nome: Presidente Médici, em homenagem ao Presidente do Brasil naquele ano, Emílio Garrastazu Médici. Já no início de 1978 passa a ser distrito do município de Ji-Paraná. Tornouse município em 6 de junho de 1981, pela Lei nº 6921, mantendo o mesmo nome. 


\subsection{OS PRIMÓRDIOS DA HISTÓRIA DA EDUCAÇÃo EM PRESIDENTE MÉDICI}

A história da educação no município se inicia com a chegada do Sr. Noé dos Santos, sua esposa Perolina da Silva Santos e seus quatorze filhos (oitos homens e seis mulheres). Vindos do Mato Grosso do Sul, aqui se instalaram, em 18 de julho de 1971, em "uma terra abençoada, de solo fértil, onde havia fartura e abundância de alimentos", como descreve Moreira (2004, p. 21).

O senhor Noé viu a necessidade de uma escola na região e consegue autorização para o seu funcionamento na sala de sua casa. Esta se tornou a primeira escola de Presidente Médici. O primeiro professor a lecionar ali se chamava Rodolfo Rufino, que logo precisou ir embora da região em função da saúde de sua esposa, mas antes de partir deixa o cargo para a filha do Sr. Noé, Evanize, que assume o posto de professora.

Diante da necessidade da construção de um espaço escolar na localidade, por meio do Decreto $\mathrm{n}^{\circ}$ 627, de 26 de setembro de 1972, assinado pelo então Governador João C. M. Henriques e pelo Secretário de Educação Leônidas R. Jaudy, é criada a Escola Isolada 15 de Novembro. Nos períodos matutino e vespertino funcionava para as turmas de $1^{\mathrm{a}}$ a $3^{\mathrm{a}}$ séries e, a noite, para o Movimento Brasileiro de Alfabetização (MOBRAL). Vale lembrar que no mesmo espaço também funcionava o Templo da Igreja Batista, do qual a família do Sr. Noé era membro.

Tempos depois, localmente é desencadeado um conflito religioso. Para Marc Bloch (2001), os conflitos, as crises e crenças que levantam discussões acerca de diferentes aspectos e possibilitam maior clareza para a história, pois "a pacífica continuidade de uma vida social sem rasgos de febre mostra-se menos favorável do que às vezes se acredita à transmissão da memória" (BLOCH, 2001, p 85).

Mas, o que houve?

No espaço onde estava instalada a escola 15 de Novembro, também funcionava a Igreja Batista. Muitos pais de alunos, de origem Católica, decidiram retirar seus filhos para que não sofressem influências de outra religião. Como consequência, a escola 15 de Novembro é transferida para um barracão da Igreja Católica e outra professora é nomeada, Dona Maria Mercedes. Alguns alunos permaneceram no antigo local e uma nova instituição educacional com o nome Escola Maria Zulima Silveiro Pinheiro é criada, sob o comando da Professora Evanize. Entretanto, o preconceito religioso separou alunos evangélicos e católicos por pouco tempo. 
O crescente fluxo migratório na região e a eminente necessidade de vagas e de novos espaços fazem com que se construa uma nova escola, o Grupo Escolar Argeu Macedo, unidade que se referencia pedagogicamente à reforma educacional paulista nos anos de 1890. Essa nova instituição passa a receber alunos das duas escolas.

Assim, a educação no município foi se moldando, melhorias foram sendo realizadas pela atuação governamental e mesmo pela sociedade civil que ali se formava.

\subsection{A Escola de $1^{\circ}$ Grau Floriano Peixoto: Seu contexto e Realidade}

Concernente ao nosso objetivo geral caracterizado em investigar os vestígios do ensino de Matemática numa escola rural situada em Presidente Médici-Rondônia, vale ressaltar que a história da educação que se delineou pelo país, e em cada localidade, vai sendo (re)significada por meio de articulação entre a história global e a história local.

[...] uma das práticas possíveis da história global se apega às passagens entre mundos muito distantes uns dos outros, ou mesmo reconhece nas situações mais locais as interdependências que as ligam ao longe, sem que necessariamente os atores tenham clara percepção disso (CHARTIER, 2010, p. 57).

Os primeiros grupos escolares criados no Brasil nos anos finais do século XIX trazem influências também para Rondônia e chegam ao interior amazônico, em específico ao município de Presidente Médici. Em 05 de dezembro de 1984, por meio do Decreto nº 2.553, foi criada na Zona Rural, pelo Pró-Rural, a Escola de $1^{\circ}$ Grau Floriano Peixoto, localizada na Linha 110, Gleba 44, Lote 55, Setor Riachuelo. Essas influências são facilmente observáveis no desenrolar da caracterização escolar.

Figura 1 - Escola de $1^{\circ}$ Grau Floriano Peixoto

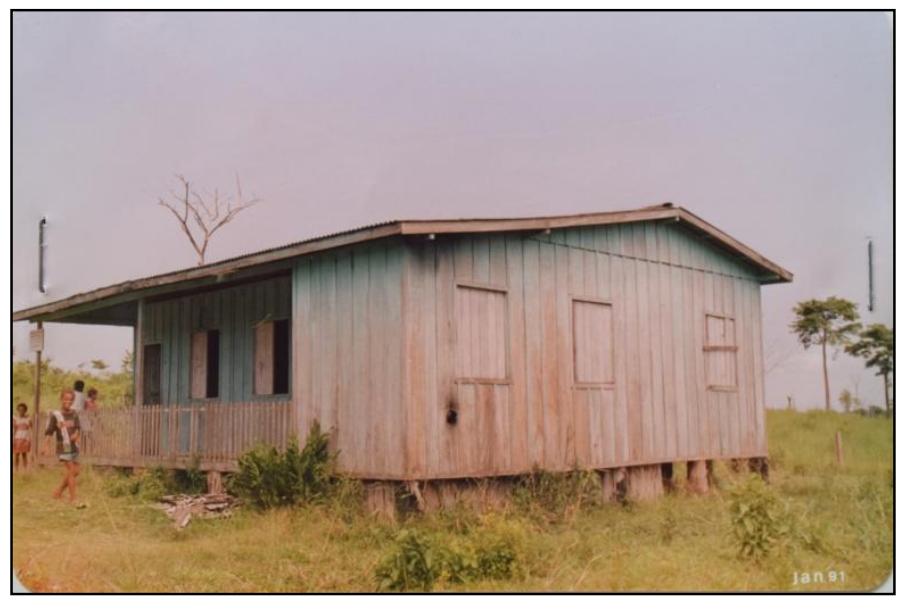

Fonte: SEDUC

Consta em seus documentos que possuía uma área construída de $82 \mathrm{~m}^{2}$ e sua estrutura era toda em madeira, contendo uma única sala de aula. Dado o inverno amazônico, foi 
construída sobre palanques de madeira para evitar a entrada de água. Inicialmente o piso era forrado por assoalhado, substituído anos depois, em uma ação comunitária, por piso em concreto. Sua cobertura, feita com telhas de amianto, o abastecimento de água provinha de poço e o sanitário era fossa negra. Era um espaço arquitetônico precário, assim como de forma global acontecia em outros locais:

\begin{abstract}
A história tradicional do ensino constantemente destacou os limites impostos às práticas pedagógicas pela rusticidade dos locais escolares, pelo estado sumário do mobiliário, pela insuficiência do material pedagógico e pela característica irregular dos livros de aula trazidos pelas crianças (CHERVEL, 1990, p. 194).
\end{abstract}

Muitas escolas de ensino primário na zona rural, somente possuíam até a $3^{\text {a }}$ série, tendência da chamada escola isolada. Os primeiros Grupos Escolares funcionavam com um sistema conhecido como seriação, isto é, "o agrupamento dos alunos nas turmas de acordo com seu o grau de conhecimento medido por meio de exames" (PEZZIN; FILHO, 2012, p. 3). Assim, as turmas $1^{\mathrm{a}}$ a $4^{\mathrm{a}}$ séries do $1^{\mathrm{o}}$ grau (atualmente anos iniciais do ensino fundamental) ficaram conhecidas como salas multisseriadas por funcionarem juntas numa mesma sala, onde todos os alunos eram instruídos por uma única professora.

O papel da mulher na educação fica evidenciado na história desta escola, pois durante todo o seu funcionamento, somente lecionaram mulheres (seis professoras), ficando clara a feminização do magistério enquanto profissão iniciada no final do século XIX, presente em toda a história da educação.

Mas qual o intuito em caracterizar historicamente uma escola rural já fechada?

Porque seria inadmissível a presente construção histórica sem a presença e compreensão deste espaço arquitetônico onde funcionou a escola, concebendo que por "onde o homem passou e deixou alguma marca da sua vida e inteligência, aí está a história” (LE GOFF, 2003, p. 107). Vale lembrar ainda a importância da condição de testemunha ocular da primeira autora deste trabalho com vivência de dois anos neste espaço escolar e considerando ainda que:

\begin{abstract}
A evolução arquitetônica, a gestão/adaptação dos espaços e das estruturas, os ciclos de procura de instrução, os ciclos de renovação dos recursos humanos e materiais, [...] são factos, acontecimentos e combinatórias que de igual modo, não apenas não podem ser deixados de fora na preparação do discurso, integrador e problematizante da síntese histórica, como de informação e vias de estruturação da investigação (MAGALHÃES, 1999, p. 69),
\end{abstract}

De que maneira se delineou o espaço temporal do presente trabalho?

A temporalidade da presente pesquisa tem início a partir do ano de 1984, quando foi a criada a Escola Floriano Peixoto, seguindo até o fechamento da escola no ano de 1998. Essa delimitação temporal não foi escolhida ao acaso, mas estabelecida pela própria história, pois 
"na medida em que nos limitamos a estudar, no tempo, cadeias de fenômenos aparentados, o problema é, em suma, simples. É a esses próprios fenômenos que convém solicitar seus próprios períodos" (BLOCH, 2001, p. 150), tomando cuidado para não forçar a delimitação como mera alusão de períodos, mas sim aos importantes fenômenos históricos ou ponto de inflexão.

Nossa condição de testemunha ocular enquanto ex-aluna da escola nos dão elementos para fazer algumas inferências, afinal "todo conhecimento da humanidade, qualquer que seja, no tempo, seu ponto de aplicação, irá beber sempre nos testemunhos dos outros uma grande parte de sua substância” (BLOCH, 2001, p. 70). Todavia, para que não ficasse uma visão restrita a uma única pessoa, buscamos outro depoimento por meio de entrevista com a professora Onisse Leite Antônio, docente que mais tempo lecionou na escola, de 1991 a 1998. Vale salientar que nos primeiros anos de atuação a professora não tinha formação em nível superior:

Cristiane: Qual era sua formação quando começou a atuar na escola?

Professora: Era leiga, só tinha a $4^{\mathrm{a}}$ série e entrei como serviço prestado, sem contrato. O contrato só veio em 1993 por seis meses. Quando vencia, eu tinha que refazer para mais seis. Em 1994 fiz o concurso e passei (Entrevista realizada por ex-aluna à professora, 2015).

No tocante à criação das escolas, ao iniciar a "implantação da educação no município, faltavam professores habilitados para trabalharem nas escolas, havendo a necessidade da contratação dos mesmos sem a devida capacitação, se comprometendo o estado de Rondônia a capacitá-los mais tarde" (LOPES; RIBEIRO, 2014, p. 46-47). Foi o que aconteceu com a professora da escola quando se graduou em Pedagogia.

A história local é rica por suas especificidades e "a origem de cada instituição escolar, quando decifrada, costuma nos oferecer várias surpresas" (SANFELICE, 2006, p. 23). Por se tratar de uma escola rural, a condição social dos alunos permeava por peculiaridades que valem ser destacadas.

Por volta dos anos de 1980, os moradores da região onde se encontrava a escola eram pessoas de baixa e média renda, sitiantes que viviam da agricultura e pecuária. Portanto, as crianças e adolescentes vinham de famílias que tiravam sua subsistência do trabalho com a terra. A situação dessas famílias por vezes numerosas dificultava ainda mais o sustento e exigia o máximo de mão de obra, o que levava muitas crianças a abandonarem a escola, caindo por terra o "[...] discurso de igualdade de oportunidades - intensamente proclamado por professores e pelas políticas republicanas - não se articulavam esforços para a igualdade de condições" (GARNICA; SOUZA, 2012, p. 112). 
Os obstáculos que os alunos tinham em frequentar assiduamente a escola poderiam prover de terem que auxiliar nos trabalhos na roça ou no trato com animais, restando-lhes pouco tempo a ser dedicado aos estudos, ocasionando na desistência ou em reprovações. Outra peculiaridade era o ingresso de alunos com idade avançada nas séries iniciais, por não haver antes, naquela localidade, nenhuma escola.

Acerca das condições em que se dão algumas das reprovações, a professora Onisse nos traz outro importante ponto de inflexão ao relatar que:

Professora: a maioria das reprovações acontecia nas $1^{\mathrm{a}} \mathrm{e} 2^{\mathrm{a}}$ séries. Tinham alguns deles que ficavam três anos retidos na mesma série. Só podiam sair da série quando estivessem aptos, sabendo ler, escrever e reconhecer o básico da matemática (Entrevista realizada por ex-aluna à professora, 2015).

Rondônia vivenciou na década de 1980 um intenso movimento migratório, grupos familiares de agricultores chegavam ao município enquanto outros saiam em busca de melhores condições de vida. Essa migração traz reflexos negativos à escola, quando no ano de 1990 a queda no número de alunos é tão sentida que restaram apenas nove crianças matriculadas e, destas, três foram reprovadas.

Apesar destes percalços, o papel da comunidade era importante nas atividades escolares. A proximidade familiar garantida nos primeiros anos de funcionamento trouxe uma relação simples, respeitosa e atenciosa, podendo ser reconhecida no trecho verbalizado pela professora Onisse:

Professora: Eu era diretora, secretária e cozinheira. Tudo ao mesmo tempo eu era na escola! Porque não tinha quem mais resolvesse. Naquele tempo, era muito mais fácil de trabalhar do que hoje. Lá eu trabalhava com as quatro séries na mesma sala. E mesmo assim era mais fácil lidar com os alunos, porque os pais estavam sempre lá ajudando. Quando surgia um problema ou eu ia à casa do aluno, ou pedia que os pais viessem à escola, e eles vinham! Hoje cada problema tem que ser passado por muita gente antes de chegar aos pais. Isso quando chega. É mais fácil resolver um problema quando a gente conversa diretamente com os pais (Entrevista realizada por ex-aluna à professora, 2015).

Em 1994 a escola registrou um aumento considerável no número de matriculados, chegando a 18 alunos. Destes, seis adentraram o âmbito escolar na $1^{\text {a }}$ série. Esta circunstância está relacionada ao aumento familiar, em que estas eram crianças nascidas no local, filhos das famílias que ainda residiam ali.

Em 1998, ano em que na condição de aluna chegamos à escola, este aumento de número de alunos não era mais sentido e, considerando ainda a construção de outra escola mais ampla e organizada, (possuía salas distintas a cada série), a Escola Floriano Peixoto fechou o seu funcionamento, sendo os seus poucos alunos restantes, transferidos. 


\subsection{O ensino de Matemática na Escola de $1^{\circ}$ Grau Floriano Peixoto}

A construção histórica do ensino, "longe de ligar a história da escola ou do sistema escolar às categorias externas, ela se dedica a encontrar na própria escola o princípio de uma investigação específica" (CHERVEL, 1990, p. 184). Imersos nesta busca: "Um primeiro desafio que essa história coloca ao historiador é a escolha de documentos que contenham vestígios da prática cultural investigada" (PINTO, 2014, p. 131).

Mas como construir uma história a partir do ensino de matemática?

Esta construção deve partir das representações sobre os processos de ensino e aprendizagem da matemática e da sua importância dessa prática nos mais diversos tempos, onde o conhecimento do passado pode melhorar as práticas do presente (VALENTE, 2013).

As dificuldades encontradas na construção da história estão na limitação da localização das produções escolares, porém devemos fazer flecha com qualquer graveto (JULIA, 2001), sendo necessária a análise de vários vestígios, sejam eles registros da escola, de alunos ou professores. Com esta concepção e intentando legitimar a presente pesquisa, analisamos enquanto fonte documental, um caderno de atividades de propriedade da autora referente ao ensino de Matemática na escola, merecendo destaque por sua importância como fonte primária.

Em entrevista realizada com a professora ao ser questionada sobre: Como se dava o ensino, principalmente de matemática nesta escola, ela nos afirmou que:

\footnotetext{
Professora: Eu passava a tarefa para a $1^{\mathrm{a}}$ série muitas vezes no caderno, outra hora no quadro, com desenhos para eles copiarem, para desenvolverem a coordenação motora. Vocês desenhavam círculos, quadrados, pintavam. Tinha cartilhas com letras e números pontilhados, desenhos referentes aos números. Eu usava muito o quadro (Entrevista realizada por ex-aluna à professora, 2015).
}

$\mathrm{Na}$ falta de material didático para todos os alunos, a professora encontrava uma metodologia reproduzindo o conteúdo no quadro de giz. Por vezes, os alunos sentavam em grupos para compartilhar os livros que eram em pequena quantidade. Quanto ao seu método de ensino de Matemática, a professora destaca:

Professora: Prefiro o modo tradicional de dar aula e avaliar, minhas aulas sempre foram assim. Eu dava os conteúdos, explicava até tirar as dúvidas dos alunos, passava exercícios, tarefas para casa e depois aplicava prova, que era bimestral (Entrevista realizada por ex-aluna à professora, 2015).

Neste depoimento podemos reconhecer um modo conservador de ensino, talvez sejam vestígios do Movimento da Matemática Moderna que chega ao Brasil por volta da década de 1960. Vale reiterar que as práticas da professora Onisse não se davam somente de modo tradicional, mas mesclando tendências, construindo seu próprio ideário pedagógico: 
Embora, nesse processo de mutação, algumas concepções/crenças permaneçam inalteradas, no geral, o ideário pedagógico de uma pessoa ou grupo é sempre efêmero, pois representa apenas as ideias que foram dominantes num determinado momento histórico (FIORENTINI, 1995, p. 29).

A transição entre diferentes práticas do ensino de matemática foram identificadas a partir da análise de uma fonte primária que é o caderno da primeira autora deste trabalho à época aluna da escola.

Figura 2 - Primeiras páginas do caderno de matemática

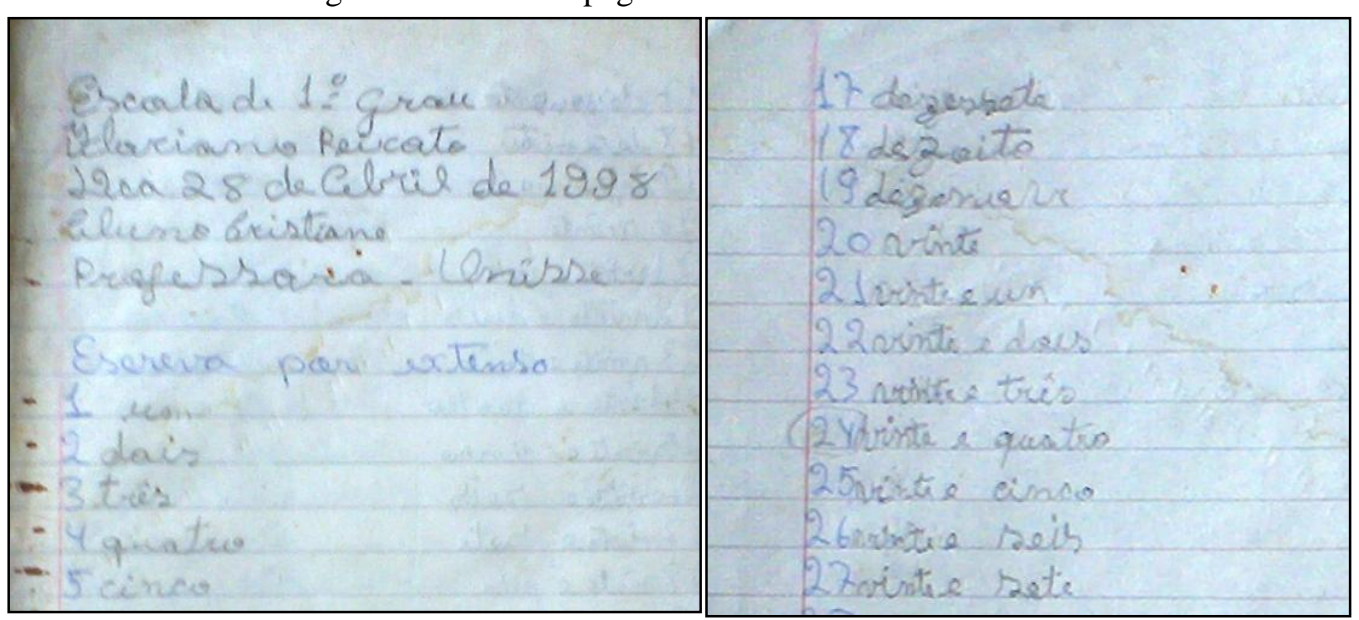

Fonte: Arquivo pessoal dos autores

Podemos observar, na figura 2, vestígios do ensino de matemática numa tendência mais tradicionalista, partindo da formação do cabeçalho como precedente de cada aula, onde o aluno é levado a conceber o âmbito que vivencia, no caso, a escola, bem como sua situação perante aquele que vem como transmissor de conhecimento, a professora. Neste modelo é esperado do aluno "um comportamento passivo, cujo aprendizado consistia na memorização e na reprodução precisa dos raciocínios e procedimentos ditados pelo professor ou pelo livro" (FIORENTINI, 1995). Mas também, nestas páginas, distinguimos um processo bem característico da pedagogia, a alfabetização, que aqui se faz no conhecimento da escrita numérica.

A proposta apresentada na figura 2 pode ser considerada importante na fase inicial da vida letiva, pois na infância quase sempre "a identificação do símbolo numérico precede a habilidade escrita. Experiências devem ser exploradas [...]. O recobrimento com o dedo ou com o corpo desse traçado pode ajudar as crianças a desenvolverem essa competência” (BERTONI, 2007, p. 17-18) de alfabetização matemática.

As imagens mostradas na figura 3 elucidam a preocupação da professora em (re)organizar o processo de aprendizagem dos seus alunos em relação à construção do conceito de números. 
Figura 3 - Sistema decimal: reconhecimento inicial

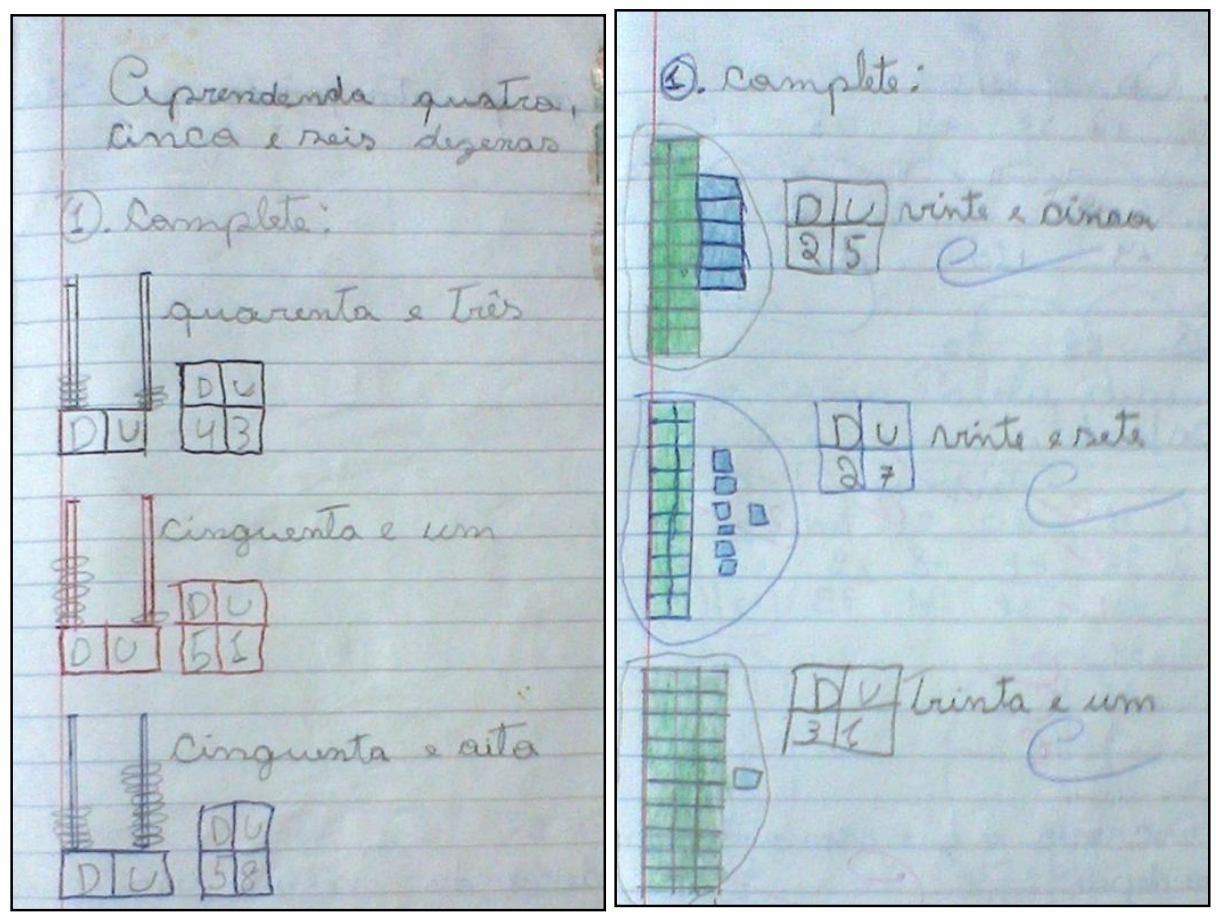

Fonte: Arquivo pessoal dos autores

Outro vestígio perceptível ainda na figura 3 é a inexistência, na escola, do material dourado criado por Maria Montessori, restando à professora apenas desenhá-lo na lousa. Neste desenho as fileiras agrupadas com dez quadrados representam a formação das dezenas e cada quadrado unitário representa a unidade. O trabalho com esse tipo de material pode tornar simples a compreensão do sistema decimal se for bem conduzido pelo professor.

A professora, mesmo sem perceber foi construindo um ideário pedagógico concernente ao conhecimento matemático por meio da contextualização (figura 4).

Figura 4 - O uso de problemas como recurso de contextualização matemática

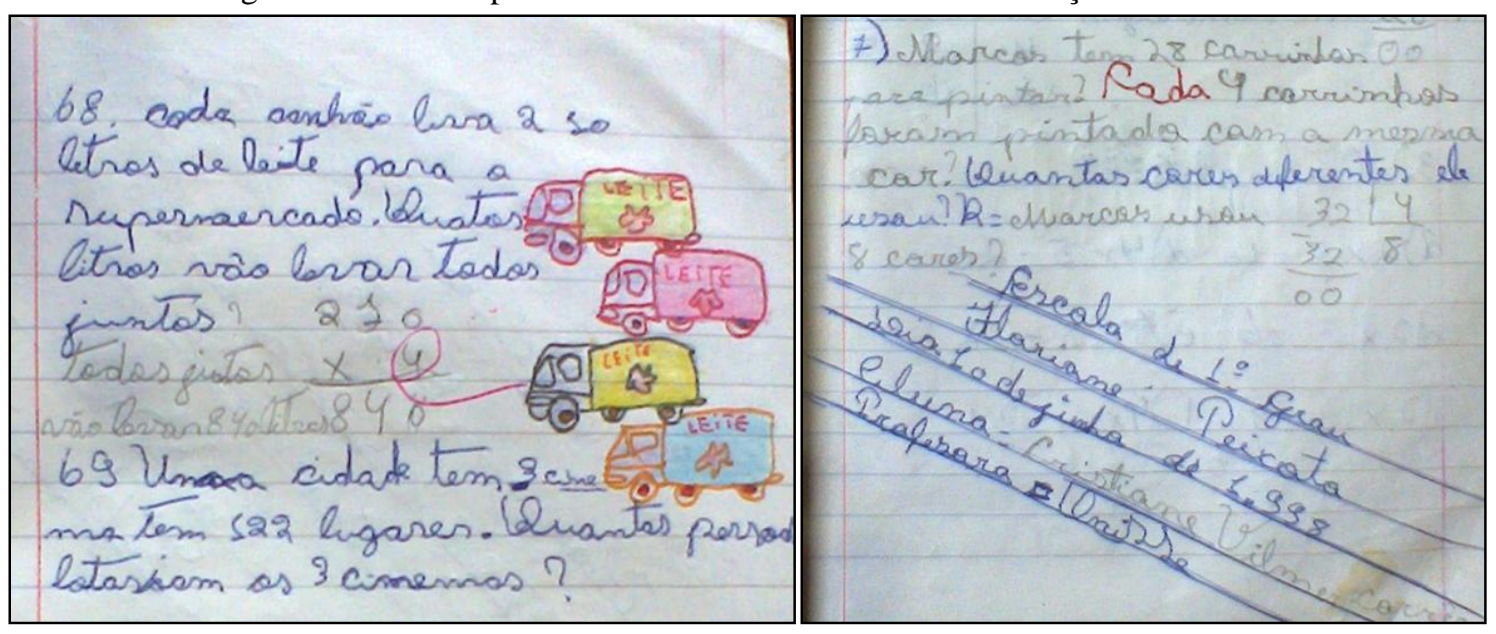

Fonte: Arquivo pessoal dos autores 
O emprego da resolução de problemas é encontrado nas práticas pedagógicas da professora, que o faz como opção de elucidar a utilização das operações matemáticas. Concebe que o aluno não chega vazio à sala de aula como uma tábula rasa, ou um papel em branco, mas traz consigo uma construção natural de matemática e de números. Portanto, é necessário "que se vivenciem esses conhecimentos, que se reflita sobre eles, que se possa conflitá-los, que sejam mentalizados em níveis sucessivos de compreensão e aprendizagem" (BERTONI, 2007, p. 13), cabendo ao docente proporcionar situações que levem o aluno a relacionar o conteúdo com práticas do dia a dia.

Intrinsecamente nas páginas do caderno apresentadas da figura 4, é perceptível a presença de uma metodologia de ensino embasada nas tendências recomendadas pelas propostas educacionais atuais, como forma de dar utilidade aos conteúdos de ensino, onde o professor não é o centro, mas se mostra preocupado com a aprendizagem de seus alunos. Podemos ainda destacar como possível cerne da resolução de problemas não somente o desenvolvimento do cálculo, das operações, mas principalmente a compreensão do seu conteúdo (GARNICA; SOUZA, 2012).

\section{CONSIDERAÇÕES FINAIS}

A presente investigação possibilitou a construção de uma história do ensino de matemática presente numa escola rural denominada Escola de $1^{\circ}$ Grau Floriano Peixoto, localizada no município de Presidente Médici, em pleno interior da Amazônia brasileira. Todavia se constituiu não como uma história isolada, mas percebendo sua influência a partir da história da Educação no Brasil, perpassando ainda pela história da Educação do estado de Rondônia e, consequentemente, do município.

O contexto desenvolvido permitiu conhecer e identificar localmente algumas características de Grupos Escolares no âmbito escolar abordado, tais como o sistema de seriação das salas de aula e da presença da $1^{\mathrm{a}}$ a $4^{\mathrm{a}}$ séries. Os grupos escolares se constituíram como um dos mais importantes pontos de inflexão da história da educação brasileira e se espalharam pelo país a partir da década de 1890 .

Também pode ser reconhecido o papel da mulher, que perante todo o enredo histórico elucidado, sofreu com a discriminação social, muitas vezes de forma abrupta. Mesmo assim, que veio tecendo caminhos para a sua consolidação como possuidora de autonomia educacional (feminização do magistério), deixando vestígios em todo o campo escolar, mesmo os mais atuais em que sua presença é marcante. 
Por intermédio da narrativa da professora foi possível identificar fatos da vivência escolar, o cotidiano de suas práticas, as políticas pedagógicas que regimentavam seu ofício, bem como a relação da escola com a sociedade. Ela propicia o conhecimento de detalhes simples, mas de grande importância. Seu exercício de memória faz com que sejam recordadas histórias próprias de cada leitor, permitindo que cada um trouxesse à tona seus signos e significados.

O processo educacional desenvolvido localmente perpassou por influências e oscilações ocorridas nos mais diversos âmbitos, estadual, nacional ou global, demonstrando uma característica não linear, entre o passado e o presente. Foram muitos os caminhos percorridos pela educação brasileira, trazendo resquícios para a educação no estado e no município de Presidente Médici. O enredo da ocupação territorial rondoniense demonstrou que a implantação de um sistema educacional decorreu do seu desenvolvimento socioeconômico e como resposta às exigências de suas necessidades.

Os vestígios do ensino de matemática na escola vêm à tona em meio às imagens e no depoimento da professora retratando um pouco da pedagogia utilizada nas aulas. Os conteúdos eram enfatizados quanto ao sistema decimal, contagem e escrita e nas quatro operações fundamentais: subtração, adição, divisão e multiplicação, levando ao aluno práticas básicas da construção numérica. A professora por vezes fez uso da resolução de problemas e de imagens, como forma de contextualizar a matemática na vivência de cada aluno. Construiu uma aprendizagem a partir da alfabetização numérica inicial de seus aprendizes, demonstrando não somente uma preocupação com a quantificação, mas também com sua expressão escrita, num simbolismo que propiciou o reconhecimento múltiplo da matemática.

A chegada de novas escolas na zona rural e a saída dos alunos dos sítios para estudarem nas cidades foram elementos culminantes para o fechamento da escola (ruptura), assim como ocorreu com várias outras. Hoje a educação rural está na presença das chamadas Escolas Polos e algumas Escolas Família Agrícola, estas últimas resistindo ao êxodo rural.

Vale reiterar a importância que além da construção da presente história, este trabalho também se abre a um vasto campo de estudo em áreas pedagógicas e históricas, trazendo visibilidade e reconhecimento de sua importância no contexto local. Todavia, pode se considerar que atendendo ao objetivo proposto, esta construção ressalta a necessidade de se produzir enredos a partir da Educação Matemática em áreas rurais da região, onde se possa gerar o interesse de professores, alunos e de toda a sociedade. 


\section{REFERÊNCIAS}

BERTONI, Nilza Eigenheer. Educação e linguagem matemática II: numerização. Brasília: Universidade de Brasília, 2007.

BLOCH, Marc. Apologia da história, ou, O ofício do historiador. Rio de Janeiro: Zahar, 2001.

CHARTIER, Roger. A história ou a leitura do tempo. 2. ed. Belo Horizonte: Autêntica, 2010.

CHERVEL, André. História das disciplinas escolares: reflexões sobre um campo de pesquisa. Teoria \& Educação, 2, 177-229, 1990.

FIORENTINI, Dario. Alguns modos de ver e conceber o ensino da Matemática no Brasil. Zetetiké, Campinas. UNICAMP, ano 3, n. 4, p. 1-37. 1995.

GARNICA, Antônio Vicente Marafioti. História oral em educação matemática: um panorama sobre pressupostos e exercícios de pesquisa. Revista História Oral, v. 18, n. 2, p. 35-53, jul./dez. 2015.

GARNICA, Antônio Vicente Marafioti; SOUZA, Luzia Aparecida. Elementos de História da Educação Matemática. São Paulo: Cultura Acadêmica, 2012.

HANSEN, Joo Adolfo. A civilização pela palavra. In: LOPES, Eliana Marques Teixeira; FARIAS FILHO, Luciano Mendes; VEIGA. Cynthia Greive. 500 anos de educação no Brasil. Belo Horizonte: Autêntica, 2000.

ISO: Instituto Nacional de Estudos e Pesquisas Educacionais Anísio Teixeira. Sinopse Estatística da Educação Superior 2016. [online]. Brasília: Inep, 2017. [citado 2018-0530]. Disponível em: 〈http://portal.inep.gov.br/basica-censo-escolar-sinopse-sinopse〉 Acesso em 12 de outubro de 2017.

JULIA, Dominique. A cultura escolar como objeto histórico. Revista Brasileira de História da Educação, v. 1, n. 1, p. 9-43, jan./jun. 2001.

LE GOFF, Jacques. História e memória. 5. ed. Campinas: Editora da UNICAMP, 2003.

LIMA, Abnael Machado de. Achegas para a História da Educação no Estado de Rondônia. 2. ed. Porto Velho/RO: Gráfica Palmares, 1993.

LOPES, Erika Maria; RIBEIRO, Emerson da Silva (orientador). Ensinar e aprender matemática em Presidente Médici durante as décadas de 1980 a 2010 na visão de professores desse período. Trabalho de Conclusão de Curso (Licenciatura em Matemática) Universidade Federal de Rondônia, Ji-Paraná, 2014.

MAGALHÃES, Justino Pereira. Contributo para História da Instituições Educativas - Entre a memória e o arquivo. In: FERNANDES, Rogério; MAGALHÃES, Justino. (Org.). Para a História do Ensino Liceau em Portugal. Actas dos Colóquios do I Centenário da Reforma de Jaime Moniz (1854-1895). Braga: Universidade do Minho, 1999. 
MATIAS, Francisco. Pioneiros: ocupação humana e trajetória política de Rondônia. Porto Velho/RO: Gráfica e Editor Maia Ltda, 1998.

MOREIRA, Nara Isabel. Um reencontro com a educação de Presidente Médici (a história que ninguém havia contado). Presidente Médici/RO, 2004.

OLIVEIRA, Dalila Andrade. As Políticas Educacionais no Governo Lula: rupturas e permanências. RBPAE, v. 25, n. 2, p. 197-209, maio/ago. 2009.

PEZZIN, Ana Cláudia; FILHO, Moysés Gonzaga Siqueira. Vestígios do Ensino de Matemática em um Grupo Escolar Capixaba. Espírito Santo, 2012.

PINTO, Neuza Bertoni. História das disciplinas escolares: reflexão sobre aspectos teóricometodológicos de uma prática historiográfica. Rev. Diálogo Educ., Curitiba, v. 14, n. 41, p. 125-142, jan./abr. 2014

SANFELICE, José Luís. História, instituições escolares e gestores educacionais. Revista HISTEDBR On-line, Campinas, n. especial, p. 20-27, ago. 2006. Disponível em <http://www.histedbr.fae.unicamp.br/art4_22e.pdf> Acesso em 14 maio. 2013.

VALENTE, Wagner Rodrigues. Oito temas sobre História da Educação Matemática.

REMATEC: Revista de Educação Matemática, Ensino e Cultura, v. 8, n. 12, p. 22-50, jan./jun. 2013.

Recebido em: 26 de fevereiro de 2019. Aprovado em: 22 de maio de 2019. 